\title{
Low incidence of venous thrombosis but high incidence of arterial thrombotic complications among critically ill COVID-19 patients in Singapore
}

Chuen Wen Tan ${ }^{1 \dagger}$, Bingwen Eugene Fan ${ }^{2,3 \dagger}$, Winnie Z. Y. Teo ${ }^{4,5}$, Moon Ley Tung ${ }^{4}$, Humaira Shafi ${ }^{6}$, Dheepa Christopher ${ }^{2,3}$, Shuwei Zheng ${ }^{7}$, Wee Ming Peh ${ }^{7,8}$, Stephrene Seok Wei Chan², Vanessa Cui Lian Chong ${ }^{2}$, Christian Aledia Gallardo ${ }^{2}$, Cheng Chieh Ray Chang ${ }^{2}$, Li Min Ling ${ }^{9}$, Jing Yuan Tan ${ }^{10}$, Ken Cheah Hooi Lee ${ }^{10}$, Ghee Chee Phua ${ }^{10}$, Benjamin Pei Zhi Cherng ${ }^{11}$, Jenny Guek Hong Low ${ }^{11,12}$, Vui Kian Ho ${ }^{8}$, Vishnu Prasad ${ }^{3}$, Lester Jung Long Wong ${ }^{13}$, Cheryl Xiu Qi Lim ${ }^{4}$, Yen Lin Chee ${ }^{4}$, Kiat Hoe Ong ${ }^{2}$, Lai Heng Lee ${ }^{1}$, Heng Joo Ng ${ }^{1 *}$, Eng Soo Yap Y,14,15* $^{4}$ and on behalf of the Thrombosis Haemostasis Workgroup of Singapore Society of Haematology

\begin{abstract}
Background: Arterial and venous thrombosis are reported to be common in critically ill COVID-19 patients.

Method and results: This is a national multicenter retrospective observational study involving all consecutive adult COVID-19 patients who required intensive care units (ICU) admission between 23 January 2020 and 30 April 2020 in Singapore. One hundred eleven patients were included and the venous and arterial thrombotic rates in ICU were $1.8 \%(n=2)$ and $9.9 \%(n=11)$, respectively. Major bleeding rate was $14.8 \%(n=16)$.

Conclusions: Critically ill COVID-19 patients in Singapore have lower venous thromboembolism but higher arterial thrombosis rates and bleeding manifestations than other reported cohorts.
\end{abstract}

Keywords: COVID-19, Thrombosis, Critical care

\section{Introduction}

COVID-19 is associated with hypercoagulability [1] and a high incidence of thrombotic complications in critically ill patients [2]. Initial reports in Western populations suggest thrombotic rates as high as $49 \%$ despite

\footnotetext{
* Correspondence: ng.heng.joo@singhealth.com.sg;

eng_soo_yap@nuhs.edu.sg

${ }^{+}$Chuen Wen Tan and Bingwen Eugene Fan contributed equally to this work.

'Department of Haematology, Singapore General Hospital, Singapore,

Singapore

${ }^{4}$ Department of Haematology-oncology, National University Cancer Institute, Singapore, Singapore

Full list of author information is available at the end of the article
}

thromboprophylaxis [3] while deep vein thrombosis (DVT) rate of $46 \%$ have been reported by the Chinese [4]. These disconcerting findings have prompted suggestion for empiric escalation of prophylactic anticoagulation therapy [3] but expert consensus [5, 6] and more recent data have questioned this rationale [7]. Of concern is hypercoagulability overlapping with sepsisinduced coagulopathy and thrombotic microangiopathy, resulting in a dynamic haemostatic environment with higher potential for bleeding complications from interaction with pharmacological thromboprophylaxis. Accurate profiling of thrombotic and bleeding

(c) The Author(s). 2021 Open Access This article is licensed under a Creative Commons Attribution 4.0 International License, which permits use, sharing, adaptation, distribution and reproduction in any medium or format, as long as you give appropriate credit to the original author(s) and the source, provide a link to the Creative Commons licence, and indicate if changes were made. The images or other third party material in this article are included in the article's Creative Commons licence, unless indicated otherwise in a credit line to the material. If material is not included in the article's Creative Commons licence and your intended use is not permitted by statutory regulation or exceeds the permitted use, you will need to obtain permission directly from the copyright holder. To view a copy of this licence, visit http://creativecommons.org/licenses/by/4.0/ The Creative Commons Public Domain Dedication waiver (http://creativecommons.org/publicdomain/zero/1.0/) applies to the data made available in this article, unless otherwise stated in a credit line to the data. 
complications in these patients is paramount for optimal case management and outcomes.

This study describes the thrombotic and bleeding manifestations among critically ill COVID-19 patients in Singapore.

\section{Methods}

This multi-center retrospective cohort study involved all eight public general hospitals with intensive care units (ICU) in Singapore-Alexandra Hospital (AH), Changi General Hospital, Khoo Teck Puat Hospital, National University Hospital, Ng Teng Fong General Hospital, Tan Tock Seng Hospital/National Centre for Infectious Disease campus, Sengkang General Hospital and Singapore General Hospital. From 23 January 2020 through 30 April 2020, all adult patients with COVID-19 confirmed by a respiratory SARS-CoV2 RT-PCR test and were admitted to any of the ICUs were identified. The study protocol was approved by the centralized institutional review board covering all participating hospitals (protocol no. CIRB 2020-2528) except AH which only contributed data on the total number of COVID-19 ICU admission and thrombotic events. Anonymized data was provided by each participating site and pooled for analyses. Laboratory results were based on the first results available when the patients were admitted to ICU. The primary outcome was any venous or arterial thrombotic event in the ICU. Other measures included (1) any thrombotic events throughout the period of hospitalisation, (2) major and minor bleeding events during hospitalisation, (3) factors associated with thrombotic and bleeding outcomes and (4) mortality. Venous thromboembolism (VTE) was diagnosed based on clinical suspicion and confirmation by Doppler ultrasound of the extremities or computed tomography. Myocardial infarctions (MI), type I ST elevation and non-ST elevation MI, were diagnosed based on dynamic changes in cardiac enzymes and electrocardiogram while ischaemic strokes were confirmed by MRI scans. Diagnosis of these arterial events were verified by attending specialists (cardiologists and neurologists respectively). Bleeding complications were graded using the modified World Health Organization (WHO) grading system [8]. Each hospital has its own standardised ICU bundles in which patients are started on pharmacological prophylaxis. However, the attending physicians are allowed clinical discretion and those patients deemed not suitable for pharmacological thromboprophyalxis are put on mechanical prophylaxis.

Descriptive statistics were used to analyse continuous and categorical variables. Logistic regression was used to evaluate potential risk factors for the secondary outcomes. All data analyses were performed using SPSS version 23.0 (IBM, USA).

\section{Results}

One hundred eleven COVID-19 patients were admitted to the ICUs during the study period. The overall thrombotic rates in ICU were $11.7 \%$ (95\% confidence interval $(\mathrm{CI}): 7.0-19.0 \%)(n=13)$ with $1.8 \%$ (95\% CI: $0.5-6.3 \%)$ $(n=2)$ venous and $9.9 \%$ (95\% CI: $5.6-16.9 \%)(n=11)$ arterial events. Corresponding rates throughout hospitalisation, censored at 30 April 2020, were 18.0\% (95\% CI: $12.0-26.2 \%)(n=20)$ with $6.3 \%$ (95\% CI: $3.1-12.5 \%)(n=$ 7) venous and $11.7 \%$ (95\% CI: $7.0-19.0 \%)(n=13)$ arterial events. After the exclusion of cases from $\mathrm{AH}(n=3$, no thrombotic events), the remaining 108 patients contributed a total of 311.4 patient-weeks for further analysis (Table 1). As of 30 April, 70 patients (64.8\%) had been discharged while 9 had died (8\%) and 30 (27.7\%) were still hospitalized.

Two VTE events, comprising a lower limb DVT and a line-related upper limb DVT, were diagnosed in two patients in ICU, giving a VTE rate of 0.6 (95\% CI: 0.1-2.3) per 100-person-weeks. For the entire duration of hospitalization, the cumulative VTE rate rose to 2.2 (95\% CI: 0.9-4.6) per 100-patient-weeks. Of these, the majority were pulmonary embolism (Table 2). $75 \%$ of the patients received therapeutic anticoagulation after the diagnosis of VTE with 2 subsequently stopped due to bleeding complications.

The arterial thrombosis rate during ICU stay was 3.5 (95\% CI: 1.8-6.3) per 100-patient-weeks. This increased marginally during the entire hospitalization to 4.2 (95\% CI: 2.2-7.1) per 100-patient-weeks. These events were mainly MI of which one was fatal (Table 2).

The overall thrombotic complication rate in these 108 patients was 6.4 (95\% CI: 3.9-9.9) per 100-patientweeks. $46.2 \%$ patients were receiving pharmacological thromboprophylaxis at the time of the events.

The major bleeding (WHO grade 3-4) rate was 5.1 (95\% CI: 2.9-8.3) per 100-patient-week. (Table 2) with an overall bleeding rate was 6.4 (95\% CI: 3.9-9.9) per 100-patient-days. One bleeding event, from an intracranial hemorrhage, was fatal.

Whilst no clinical factor was significantly associated with the occurrence of thrombotic events, the need of haemodialysis support in ICU and higher fibrinogen level were respectively associated with higher and lower risk for major bleeding events (Table 3a). Mortality was associated with thrombosis but not bleeding (Table 3b).

\section{Discussion}

Although only two-thirds of our critically ill COVID-19 patients received thromboprophylaxis, the incidence rate of VTE was only $1.8 \%$. This rate is far lower than similar published studies that included only objectively confirmed symptomatic VTE events [3, 9]. Several reasons could account for the lower VTE rates in our report. 
Table 1 Clinical characteristics and laboratory findings of 108 critically ill COVID-19 patients stratified according to their thrombosis status

\begin{tabular}{|c|c|c|c|c|}
\hline Characteristics & $\begin{array}{l}\text { All patients }(n= \\
\text { 108) }\end{array}$ & $\begin{array}{l}\text { No thrombotic events } \\
(n=88)\end{array}$ & $\begin{array}{l}\text { Venous thrombosis } \\
(n=7)\end{array}$ & $\begin{array}{l}\text { Arterial thrombosis } \\
(n=13)\end{array}$ \\
\hline \multicolumn{5}{|l|}{ Demographics } \\
\hline Age (years) & $62(19-88)$ & $61.5(19-88)$ & $62(54-75)$ & $64(40-82)$ \\
\hline Male & $75(69.4 \%)$ & $59(67 \%)$ & $5(71.4 \%)$ & $11(84.6 \%)$ \\
\hline Body weight $>100 \mathrm{~kg}$ & $6(5.6 \%)$ & $5(5.7 \%)$ & $0(0 \%)$ & $1(7.7 \%)$ \\
\hline \multicolumn{5}{|l|}{ Ethnicity } \\
\hline Chinese & $67(62 \%)$ & $55(62.5 \%)$ & $6(85.7 \%)$ & $6(46.2 \%)$ \\
\hline Malay & $14(13 \%)$ & $12(13.6 \%)$ & $1(14.3 \%)$ & $1(7.7 \%)$ \\
\hline Indian & $16(14.8 \%)$ & $12(13.6 \%)$ & $0(0 \%)$ & $4(30.8 \%)$ \\
\hline Thai/Burmese & $3(2.8 \%)$ & $3(3.4 \%)$ & $0(0 \%)$ & $0(0 \%)$ \\
\hline Others & $8(7.4 \%)$ & $6(6.8 \%)$ & $0(0 \%)$ & $2(15.4 \%)$ \\
\hline \multicolumn{5}{|l|}{ Pre-existing medical conditions } \\
\hline \multicolumn{5}{|l|}{ Major illness } \\
\hline Hypertension & $62(57.4 \%)$ & $50(56.8 \%)$ & $3(42.9 \%)$ & $9(69.2 \%)$ \\
\hline Ischaemic heart disase & $21(19.4 \%)$ & $16(18.2 \%)$ & $2(28.6 \%)$ & $3(23.1 \%)$ \\
\hline Dyslipidemia & $52(48.1 \%)$ & $40(45.5 \%)$ & $4(57.1 \%)$ & $8(61.5 \%)$ \\
\hline Heart failure & $4(3.7 \%)$ & $4(4.5 \%)$ & $0(0 \%)$ & $0(0 \%)$ \\
\hline Previous stroke & $6(5.6 \%)$ & $5(5.7 \%)$ & $0(0 \%)$ & $1(7.7 \%)$ \\
\hline Diabetes & $40(37 \%)$ & $35(39.8 \%)$ & $1(14.3 \%)$ & $4(30.8 \%)$ \\
\hline Renal impairment & $15(13.9 \%)$ & $12(13.6 \%)$ & $1(14.3 \%)$ & $2(15.4 \%)$ \\
\hline History of venous thromboembolism & $4(3.7 \%)$ & $4(4.5 \%)$ & $0(0 \%)$ & $0(0 \%)$ \\
\hline Anti-coagulant therapy at admission & $4(3.7 \%)$ & $4(4.5 \%)$ & $0(0 \%)$ & $0(0 \%)$ \\
\hline Anti-platelet agent at admission & $20(18.5 \%)$ & $15(17 \%)$ & $2(28.6 \%)$ & $3(23.1 \%)$ \\
\hline \multicolumn{5}{|l|}{ ICU-specific findings } \\
\hline APACHE ॥ & $11(0-32)$ & $10.5(0-32)$ & $11(6-27)$ & $11(4-20)$ \\
\hline SOFA & $3(0-16)$ & $3(0-12)$ & $2(0-16)$ & $4(1-9)$ \\
\hline Mechanical ventilation & $84(77.8 \%)$ & $66(75 \%)$ & $5(71.4 \%)$ & $13(100 \%)$ \\
\hline Dialysis support & $28(25.9 \%)$ & $21(23.9 \%)$ & $2(28.6 \%)$ & $5(38.5 \%)$ \\
\hline $\begin{array}{l}\text { Onset of symptoms till ICU admission in } \\
\text { days }\end{array}$ & $8(0-34)$ & $7.5(0-34)$ & $8(4-15)$ & $9(3-34)$ \\
\hline Prophylactic anticoagulation & $69(63.9 \%)$ & $59(67 \%)$ & $4(57.1 \%)$ & $6(46.2 \%)$ \\
\hline \multicolumn{5}{|l|}{ Thrombosis-related features } \\
\hline $\begin{array}{l}\text { Onset of thrombosis from hospital } \\
\text { admission in days }\end{array}$ & & & $13(7-42)$ & $7(0-25)$ \\
\hline $\begin{array}{l}\text { Onset of thrombosis from admission to ICU } \\
\text { in days }\end{array}$ & & & $7(2-23)$ & $5(0-13)$ \\
\hline \multicolumn{5}{|l|}{ Bleeding complications } \\
\hline Major bleeding events & $16(14.8 \%)$ & $10(11.4 \%)$ & $3(42.9 \%)$ & $3(23.1 \%)$ \\
\hline Minor bleeding events & $4(3.7 \%)$ & $4(4.5 \%)$ & $0(0 \%)$ & $0(0 \%)$ \\
\hline Death & $9(8.3 \%)$ & $5(5.7 \%)$ & $1(14.3 \%)$ & $3(23.1 \%)$ \\
\hline \multicolumn{5}{|l|}{ Laboratory findings, median (range) } \\
\hline PT (s) & $12.6(11.2-13.6)$ & $12.0(11.0-13.1)$ & $13.4(13.2-15.3)$ & $12.8(11.5-15.7)$ \\
\hline aPTT (s) & $36.9(32.8-41.9)$ & $36.8(32.6-41.2)$ & $33.8(32.6-38.2)$ & (39.8 (32.9-42.2) \\
\hline D-dimer (mg/L FEU) & $2.3(1.2-6.1)$ & $1.9(1.2-5.5)$ & $2.7(2.4-2.7)$ & $6.1(1.8-12.8)$ \\
\hline Fibrinogen $(g / L)$ & $5.9(4.2-8.2)$ & $6.8(4.1-8.0)$ & $4.0(2.1-5.6)$ & $6.2(4.7-9.2)$ \\
\hline
\end{tabular}


Table 1 Clinical characteristics and laboratory findings of 108 critically ill COVID-19 patients stratified according to their thrombosis status (Continued)

\begin{tabular}{lllll}
\hline Characteristics & All patients $\left(\boldsymbol{n}=\begin{array}{l}\text { No thrombotic events } \\
(\boldsymbol{n}=\mathbf{8 8})\end{array}\right.$ & $\begin{array}{l}\text { Venous thrombosis } \\
(\boldsymbol{n}=\mathbf{7})\end{array}$ & $\begin{array}{l}\text { Arterial thrombosis } \\
(\boldsymbol{n}=\mathbf{1 3})\end{array}$ \\
\hline White blood count $\left(\times 10^{9} / \mathrm{L}\right)$ & $8.5(6.1-11.7)$ & $8.3(6.0-11.1)$ & $11.3(6.5-14.9)$ & $10.5(7.5-12.9)$ \\
Absolute lymphocyte count $\left(\times 10^{9} / \mathrm{L}\right)$ & $0.9(0.6-1.5)$ & $0.9(0.6-1.5)$ & $0.9(0.6-1.5)$ & $0.9(0.6-1.7)$ \\
Absolute neutrophil count $\left(\times 10^{9} / \mathrm{L}\right)$ & $7.1(4.5-10.3)$ & $6.9(4.5-10.1)$ & $7.9(5.2-13.8)$ & $8.6(5.0-11.5)$ \\
Plaletet count $\left(\times 10^{9} / \mathrm{L}\right)$ & $221(116-350)$ & $219(161-350)$ & $232(155-385)$ & $230(160-338)$ \\
CRP $(\mathrm{mg} / \mathrm{L})$ & $158(99-249)$ & $174(97-265)$ & $142(17-198)$ & $140(114-163)$ \\
Procalcitonin $(\mu \mathrm{g} / \mathrm{L})$ & $0.5(0.2-1.3)$ & $0.5(0.2-1.3)$ & $0.2(0.2-2.3)$ & $0.6(0.2-2.1)$ \\
Creatinine $(\mu \mathrm{mo} / \mathrm{L})$ & $85(68-120)$ & $85(68-120)$ & $78(62-135)$ & $88(71-120)$ \\
\hline
\end{tabular}

Continuous variables denoted as median (range); categorical variables as number (\%)

Table 2 Description of the thrombotic and bleeding cases

\begin{tabular}{|c|c|c|}
\hline Type of event & $\begin{array}{l}\text { Number of } \\
\text { cases }\end{array}$ & Details \\
\hline Pulmonary embolism (PE) only & 4 & 4 cases of PE diagnosed on CTPA \\
\hline $\begin{array}{l}\text { PE and proximal lower limb deep vein } \\
\text { thrombosis (DVT) }\end{array}$ & 1 & 1 case had both PE and DVT \\
\hline Proximal lower limb DVT only & 1 & 1 case had both proximal lower limb DVT \\
\hline Other venous thromboembolism sites & 1 & 1 case had line related upper limb DVT \\
\hline Myocardial infarction (MI) only & 11 & 11 cases had Ml \\
\hline $\mathrm{Ml}$ and ischaemic stroke & 1 & 1 case had both $\mathrm{Ml}$ and ischaemic stroke \\
\hline Ischaemic stroke & 1 & 1 case had ischaemic stroke \\
\hline \multirow[t]{15}{*}{ Bleeding (Major) } & 16 & 1 Intracranial haemorrhage - while on IV prophylactic heparin for CVA \\
\hline & & $\begin{array}{l}2 \text { cases of intracranial haemorrhage - while on ECMO with IV unfractionated } \\
\text { Heparin }\end{array}$ \\
\hline & & 1 PR bleeding from haemorrhoids/anal fissures - while on therapeutic LMWH for PE \\
\hline & & 1 PR bleeding from haemorrhoids - while on prophylactic LMWH \\
\hline & & 1 PR bleed from haemorrhoids - not on anticoagulation \\
\hline & & 1 Severe gastritis with melena - while on S/C therapeutic LMWH for DVT \\
\hline & & 1 Recurrent Forrest $2 \mathrm{C}$ ulcer bleed - while on S/C therapeutic LMWH for DVT \\
\hline & & $\begin{array}{l}1 \text { Stress gastropathy with nasogastric tube erosion and worsening anaemia - not } \\
\text { on anticoagulation }\end{array}$ \\
\hline & & 1 Coffee ground NG aspirate related to celecoxib use \\
\hline & & 1 Coffee ground NG aspirate - not on any anticoagulation \\
\hline & & 1 Gastrointestinal bleed - not on any anticoagulation \\
\hline & & 1 Haemorrhagic encephalitis and PR bleed - while on prophylactic LMWH \\
\hline & & 1 Haemoptysis - while on prophylactic LMWH \\
\hline & & 1 Bloody trachea aspirates - while on IV unfractionated Heparin for STEMI \\
\hline & & 1 Bleeding from lines - while on IV unfractionated Heparin for IVC thrombosis \\
\hline \multirow[t]{3}{*}{ Bleeding (Minor) } & 4 & 2 cases of blood stained sputum - while on prophylactic LMWH \\
\hline & & 1 Mild haematuria after urinary catheter insertion - while on apixaban prophylaxis \\
\hline & & 1 Mild bleeding from central venous catheter - while on prophylactic LMWH \\
\hline
\end{tabular}

Acute pulmonary embolism was diagnosed with CT-pulmonary angiography, deep vein thrombosis/upper extremity vein thrombosis was diagnosed with ultrasonography, strokes were diagnosed with $\mathrm{CT}$

CT computed topography, ECMO Extracorporeal membrane oxygenation, IV intravenous, LMWH Low molecular weight heparin, NG Aspirate Nasogastric aspirate, S/ C subcutaneous, STEMI ST Elevation MI 
Table 3 (a) Odds ratio of clinical and laboratory factors for thrombotic (arterial and venous) and major bleeding events. (b) Association of thrombotic and major bleeding events to mortality

\begin{tabular}{|c|c|c|c|c|c|c|c|c|}
\hline \multirow[t]{3}{*}{ a) Factors } & \multicolumn{4}{|c|}{ Thrombotic Events } & \multicolumn{4}{|c|}{ Major Bleeding Events } \\
\hline & \multirow{2}{*}{$\begin{array}{l}\text { Odds } \\
\text { Ratio }\end{array}$} & \multicolumn{2}{|c|}{ 95\% Confidence Interval } & \multirow{2}{*}{$\begin{array}{l}P \\
\text { value }\end{array}$} & \multirow{2}{*}{$\begin{array}{l}\text { Odds } \\
\text { Ratio }\end{array}$} & \multicolumn{2}{|c|}{ 95\% Confidence Interval } & \multirow{2}{*}{$\begin{array}{l}P \\
\text { value }\end{array}$} \\
\hline & & Lower Bound & Upper Bound & & & Lower Bound & Upper Bound & \\
\hline \multicolumn{9}{|l|}{ Baseline demographics } \\
\hline Age & 1.034 & .990 & 1.080 & .13 & 1.026 & .980 & 1.075 & .27 \\
\hline Gender, male & 1.966 & .603 & 6.414 & .26 & 1.381 & .410 & 4.650 & .60 \\
\hline Ethnicity, Chinese & .900 & .333 & 2.430 & .84 & .754 & .257 & 2.207 & .61 \\
\hline Diabetes & .505 & .168 & 1.514 & .22 & .740 & .237 & 2.310 & .60 \\
\hline Hypertension & 1.140 & .424 & 3.065 & .80 & .704 & .243 & 2.040 & .52 \\
\hline Hyperlipidemia & 1.800 & .670 & 4.835 & .24 & 1.091 & .377 & 3.155 & .87 \\
\hline Renal impairment & 1.118 & .284 & 4.399 & .87 & 2.455 & .672 & 8.962 & .17 \\
\hline Pre-existing cardiovascular disease ${ }^{a}$ & 1.667 & .562 & 4.945 & .36 & .780 & .203 & 2.999 & .72 \\
\hline \multicolumn{9}{|l|}{ ICU-specific features } \\
\hline APAHCE score & .979 & .904 & 1.061 & .61 & .997 & .918 & 1.082 & .94 \\
\hline SOFA score & 1.043 & .890 & 1.224 & .60 & 1.161 & .993 & 1.358 & .06 \\
\hline Mechanical ventilation & 3.000 & .644 & 13.973 & .16 & 5.000 & .626 & 39.963 & .13 \\
\hline Dialysis support & 1.718 & .606 & 4.867 & .31 & 4.940 & 1.629 & 14.978 & .005 \\
\hline Use of thromboprophylaxis & .492 & .184 & 1.313 & .16 & .376 & .128 & 1.108 & .08 \\
\hline \multicolumn{9}{|l|}{ Laboratory findings } \\
\hline PT & 1.133 & .965 & 1.329 & .13 & 1.060 & .906 & 1.241 & .47 \\
\hline aPTT & .999 & .967 & 1.032 & .97 & 1.003 & .967 & 1.041 & .88 \\
\hline D-dimer & 1.030 & .929 & 1.143 & .57 & .783 & .454 & 1.352 & .38 \\
\hline Fibrinogen & .956 & .751 & 1.217 & .78 & .658 & .453 & .957 & .03 \\
\hline White blood count & 1.037 & .962 & 1.117 & .35 & .994 & .906 & 1.089 & .89 \\
\hline Absolute lymphocyte count & 1.246 & .698 & 2.226 & .46 & .573 & .217 & 1.511 & .26 \\
\hline Absolute neutrophils count & 1.030 & .945 & 1.123 & .50 & 1.001 & .905 & 1.107 & .99 \\
\hline Platelet count & .999 & .996 & 1.002 & .60 & .998 & .995 & 1.002 & .35 \\
\hline C-reactive protein & .995 & .989 & 1.001 & .09 & 1.001 & .995 & 1.006 & .75 \\
\hline Procalcitonin & .996 & .969 & 1.023 & .76 & .937 & .776 & 1.132 & .50 \\
\hline Creatinine & 1.000 & .996 & 1.004 & .86 & .999 & .995 & 1.004 & .78 \\
\hline b) Factors & \multicolumn{8}{|c|}{ Mortality } \\
\hline Thrombotic events & 4.150 & 1.004 & 17.161 & .05 & & & & \\
\hline Arterial events & 4.450 & .961 & 20.599 & .06 & & & & \\
\hline Venous events & 1.937 & .207 & 18.141 & .56 & & & & \\
\hline Major bleeding events & 3.308 & .735 & 14.878 & .12 & & & & \\
\hline
\end{tabular}

${ }^{a}$ Included ischemic heart disease, congestion heart failure and stroke

Previous studies have shown patients of Asian-descent have lower risk for VTE compared to Western cohorts [10]. Our patients were also younger with fewer comorbidities and they tended to present to the hospital earlier in their course of illness [3, 4, 9], which might have led to earlier interventions as reflected in the low median APACHE and SOFA scores on transfer to ICU.

Of interest, the occurrence of further VTE events after ICU stay suggest the persistence of hypercoagulability
[11]. Thromboprophylaxis measures hence should be continued for these patients throughout hospitalisation. However, a more intensified anticoagulation strategy for our patients was negated by the $14.8 \%$ major bleeding rate observed, which was considerably higher than other cohorts [7, 12] despite having lesser proportion of our patients on pharmacological thromboprophylaxis. The baseline characteristics of our patients were not notably different from other cohorts (references as above) apart 
from the ethnic factor in which our patients were predominantly Asian. The potential ethnic difference in bleeding events has also been observed in other settings including reports of higher bleeding rates among Asian patients taking warfarin for atrial fibrillation, compared with non-Asians counterparts [13].

In contrast to VTE, our arterial event rates are high with mainly MIs occurring almost exclusively in the ICU, when the patients were the sickest. Unlike VTE, comparative arterial thrombotic rates in other COVID19 cohorts are lower at $4 \%[3,7]$ with mainly strokes rather than MIs. Myocardial injury in up to $30 \%$ of COVID-19 patients have been reported by some Chinese investigators but this was based on elevation of cardiac troponin levels [14] without verification of MI. Apart from ethnic differences, the baseline cardiovascular risk factors of our patients did not differ notably from existing literature [7] and thus the precise reason behind the higher rates seen in our population is not apparent currently.

This study is limited by its retrospective nature as with most other studies conducted under the present pandemic environment. There was no established imaging protocol for suspected VTE consistent across the hospitals. Similarly, clinical and laboratory data was not uniformly collected and trivial bleeds might have been missed. The small number of thrombotic and bleeding events also limited our statistical analysis of inference.

\section{Conclusion}

Our data is adequately robust to highlight the differences in thrombosis presentations and higher bleeding manifestations compared to other published cohorts. Our findings thus argue against the need for intensification of pharmacological thromboprophylaxis in similar Asian-predominant populations. Use of global coagulation assays [15] in critically ill COVID-19 patients to guide thromboprophylaxis warrant future consideration and exploration. Extended thromboprophylaxis during hospitalisation should also be considered. The role of antiplatelets and low dose direct anti-Xa inhibitors as cardio-protectants should be among future investigations.

\section{Acknowledgments}

The authors are grateful for the full support from all the participating hospitals and are greatly appreciative of the dedication of all the healthcare workers involved in the care of COVID-19 patients.

\section{IRB information}

Protocol no. CIRB 2020-2528 under the Centralised Institutional Review Board of Singhealth.

\section{Disclosures}

All authors have no conflict of interest to declare.

\section{Authors' contributions}

CWT, BEF and ESY initiated and designed the study and had full access to all the study data and take full responsibility for the integrity of the data and accuracy of the data analysis. HJN initiated and critically revised the manuscript. WT collected and analysed the data and contributed to the writing of the manuscript. CYL and LHL critically revised the manuscript. MLT, HS, D, SZ, WMP, SSWC, VCLC, CAG, CCRC, LML, JYT, KCHL, GCP, JGHL, VKH contributed to data acquisition and interpretation. All authors reviewed and approved the final version of the manuscript.

\section{Funding}

This multicentre study was performed without any funding received.

Availability of data and materials

For original data, please contact eng_soo_yap@nuh.edu.sg.

\section{Declarations}

Ethics approval and consent to participate

Ethics approval for this multicentre study was obtained from the SingHealth Centralised Institution Review Board.

\section{Competing interests}

The authors do not declare any competing interests.

\section{Author details}

'Department of Haematology, Singapore General Hospital, Singapore, Singapore. ${ }^{2}$ Department of Haematology, Tan Tock Seng Hospital, Singapore, Singapore. ${ }^{3}$ Department of Laboratory Medicine, Khoo Teck Puat Hospital, Singapore, Singapore. ${ }^{4}$ Department of Haematology-oncology, National University Cancer Institute, Singapore, Singapore. ${ }^{5}$ Fast Program, Alexandra Hospital, Singapore, Singapore. ${ }^{6}$ Department of Infectious Diseases, Changi General Hospital, Singapore, Singapore. ${ }^{7}$ Department of General Medicine, Sengkang General Hospital, Singapore, Singapore. ${ }^{8}$ Department of Intensive Care Medicine, Sengkang General Hospital, Singapore, Singapore.

${ }^{9}$ Department of Infectious Diseases, National Centre for Infectious Disease, Singapore, Singapore. ${ }^{10}$ Department of Respiratory and Critical Care Medicine, Singapore General Hospital, Singapore, Singapore. ${ }^{11}$ Department of Infectious Diseases, Singapore General Hospital, Singapore, Singapore.

${ }^{12}$ Programme in Emerging Infectious Diseases, Duke-NUS, Singapore, Singapore. ${ }^{13}$ Division of Medicine, Khoo Teck Puat Hospital, Singapore, Singapore. ${ }^{14}$ Department of Medicine, Ng Teng Fong General Hospital, Singapore, Singapore. ${ }^{15}$ Department of Laboratory Medicine, National University Hospital, Singapore, Singapore.

Received: 13 September 2020 Accepted: 1 March 2021

Published online: 08 March 2021

\section{References}

1. Iba T, Levy JH, Levi M, Connors JM, Thachil J. Coagulopathy of coronavirus disease 2019. Crit Care Med. 2020;48(9):1358-64.

2. Al-Ani F, Chehade S, Lazo-Langner A. Thrombosis risk associated with COVID-19 infection. A scoping review. Thromb Res. 2020;192:152-60.

3. Klok FA, Kruip M, van der Meer NJM, Arbous MS, Gommers D, Kant KM, Kaptein FHJ, van Paassen J, Stals MAM, Huisman MV, Endeman $\mathrm{H}$. Confirmation of the high cumulative incidence of thrombotic complications in critically ill ICU patients with COVID-19: an updated analysis. Thromb Res. 2020;191:148-50.

4. Zhang L, Feng X, Zhang D, Jiang C, Mei H, Wang J, Zhang C, Li H, Xia X Kong $S$, et al. Deep vein thrombosis in hospitalized patients with coronavirus disease 2019 (COVID-19) in Wuhan, China: prevalence, risk factors and outcome. Circulation. 2020;142:114-28.

5. Moores LK, Tritschler T, Brosnahan S, Carrier M, Collen JF, Doerschug K, Holley AB, Jimenez D, LeGal G, Rali P, Wells P. Prevention, diagnosis and treatment of venous thromboembolism in patients with COVID-19: CHEST guideline and expert panel report. Chest. 2020;158(3):1143-63.

6. Spyropoulos AC, Levy JH, Ageno W, Connors JM, Hunt BJ, Iba T, Levi M, Samama CM, Thachil J, Giannis D, et al. Scientific and standardization committee communication: clinical guidance on the diagnosis, prevention and treatment of venous thromboembolism in hospitalized patients with COVID-19. J Thromb Haemost. 2020;18:1859-63. 
7. Al-Samkari H, Karp Leaf RS, Dzik WH, Carlson JC, Fogerty AE, Waheed A, Goodarzi K, Bendapudi P, Bornikova L, Gupta S, et al. COVID and coagulation: bleeding and thrombotic manifestations of SARS-CoV2 infection. Blood. 2020;136:489-500.

8. Miller AB, Hoogstraten B, Staquet M, Winkler A. Reporting results of cancer treatment. Cancer. 1981;47:207-14.

9. Middeldorp S, Coppens M, van Haaps TF, Foppen M, Vlaar AP, Muller MCA, Bouman CCS, Beenen LFM, Kootte RS, Heijmans J, et al. Incidence of venous thromboembolism in hospitalized patients with COVID-19. J Thromb Haemost. 2020;18:1995-2002.

10. Lee LH, Gallus A, Jindal R, Wang C. Wu CC: incidence of venous thromboembolism in Asian populations: a systematic review. Thromb Haemost. 2017;117:2243-60.

11. Pavoni V, Gianesello L, Pazzi M, Stera C, Meconi T, Frigieri FC. Evaluation of coagulation function by rotation thromboelastometry in critically ill patients with severe COVID-19 pneumonia. J Thromb Thrombolysis. 2020;50:281-6.

12. Shah A, Donovan K, McHugh A, Pandey M, Aaron L, Bradbury CA, Stanworth SJ, Alikhan R, Von Kier S, Maher K, et al. Thrombotic and haemorrhagic complications in critically ill patients with COVID-19: a multicentre observational study. Crit Care. 2020;24:561.

13. Chiang CE, Wang KL, Lip GY. Stroke prevention in atrial fibrillation: an Asian perspective. Thromb Haemost. 2014:111:789-97.

14. Bonow RO, Fonarow GC, O'Gara PT, Yancy CW. Association of Coronavirus Disease 2019 (COVID-19) with myocardial injury and mortality. JAMA Cardiol. 2020;5:751-3.

15. Mortus JR, Manek SE, Brubaker LS, Loor M, Cruz MA, Trautner BW, Rosengart TK. Thromboelastographic results and hypercoagulability syndrome in patients with coronavirus disease 2019 who are critically ill. JAMA Netw Open. 2020;3:e2011192.

\section{Publisher's Note}

Springer Nature remains neutral with regard to jurisdictional claims in published maps and institutional affiliations.

Ready to submit your research? Choose BMC and benefit from:

- fast, convenient online submission

- thorough peer review by experienced researchers in your field

- rapid publication on acceptance

- support for research data, including large and complex data types

- gold Open Access which fosters wider collaboration and increased citations

- maximum visibility for your research: over $100 \mathrm{M}$ website views per year

At $\mathrm{BMC}$, research is always in progress.

Learn more biomedcentral.com/submissions 